\title{
On representationalism, common-factorism, and whether consciousness is here and now
}

\author{
Pär Sundström ${ }^{1}$
}

Published online: 13 July 2018

(C) The Author(s) 2018

\begin{abstract}
A strong form of representationalism says that every conscious property of every mental state can be identified with some part of the state's representational properties. A weaker representationalism says that some conscious property of some mental state can be identified with some part of the state's representational properties. David Papineau has recently argued that all such theories are incorrect since (a) they construe consciousness as consisting (partly or wholly) in "relations to propositions or other abstract objects outside space and time", whereas (b) consciousness is "concrete" and "here and now". Papineau defends instead a kind of "qualia theory" according to which all conscious properties are intrinsic non-relational properties of subjects. He argues that this theory bypasses the difficulties he identifies for representationalism. Similar worries about representationalism, and similar ideas to the effect that some qualia theory, adverbial theory, or sense-datum theory fares better with respect to these worries are relatively wide-spread. I argue that Papineau's theory does not bypass the difficulties he identifies for representationalism. In fact, Papineau's theory arguably has no advantage at all over representationalism with regard to these issues. The features that concern Papineau about representationalist views do not derive-or do not derive solely-from the representationalism of these views. They (also) derive from a common-factorism of these views. And this common-factorism is embraced by Papineau as well as by most theories of consciousness and perception.
\end{abstract}

For helpful comments and discussions, I am very grateful to David Bain, Derek Brown, Torfinn Huvenes, Fiona Macpherson, Neil Mehta, David Papineau, Bram Vaassen, and an anonymous referee for this journal.

Pär Sundström

par.sundstrom@umu.se

1 The Department of Historical, Philosophical and Religious Studies, Umeå University, 90187 Umeå, Sweden 
Keywords Representationalism · Common-factor theory · Consciousness ·

Perception · Concrete $\cdot$ Abstract

\section{Introduction}

Some mental states are like something. I take a state's being like so-and-so to be a matter of its having certain properties, which I shall call conscious properties. Exactly what these conscious properties might be will be a central issue in what follows. But for now we can work with the idea that conscious properties are things that can be had by many individuals. For example, my current, token back pain's being like what it is like is a matter of its having a certain property that some other token pain of some other subject could also have. I shall sometimes also talk about the conscious character of a state, intending no distinction between conscious character and conscious properties.

Some mental states also represent things as being a certain way, or so I shall assume. I shall say that a state's representing things as being so-and-so is a matter of the state's having a certain representational properties.

A representationalist view is a view according to which there are certain connections between the representational and the conscious properties of mental states. One version is:

Strong Representationalism: For every conscious property, C, and mental state, $\mathrm{m}$ : If $\mathrm{m}$ has $\mathrm{C}$, then there is a representational property, $\mathrm{R}$, such $\mathrm{C}=\mathrm{R}$.

According to this view, what my current pain is like can be identified with some part of my pain's representational properties; for example, the property of representing my back as instantiating a certain feel.

There are many concerns about Strong Representationalism. For example, it might seem plausible that

(i) a conscious tactile perception of a certain shape could duplicate the representational properties of a conscious visual perception of that shape without duplicating the conscious properties of the latter (Crane 2000, Sect. 4)

If that is correct it falsifies Strong Representationalism because Strong Representationalism entails that duplication of a mental state's representational properties ensures duplication of any conscious properties the state might have. Similar concerns about Strong Representationalism include the thoughts that,

(ii) an unconscious perceptual state could duplicate the representational properties of some conscious perceptual state without duplicating the conscious properties of the latter (Chalmers 2004, Sect. 3),

and that, 
(iii) a blurry visual state could duplicate the representational properties of some non-blurry visual state without duplicating the conscious properties of the latter (compare Loar 2003, Sects. 6-7; Smith 2008; Crane 2009, Sect. 4).

On these or similar grounds, most philosophers reject Strong Representationalism. ${ }^{1}$ But many who do so accept the following weaker claim:

Weak Representationalism: For some conscious property, C, some mental state, $\mathrm{m}$, and some representational property, $\mathrm{R}$ : $\mathrm{m}$ has $\mathrm{C}$ and $\mathrm{C}=\mathrm{R}$.

To illustrate this view, consider a conscious, blurry, visual perception of rightward motion. If one is impressed by the thought (i) above one might accept that the visual conscious character of this state is not a representational property. Similarly, if one is impressed by the thoughts (ii) and (iii) one might accept that what makes this a conscious rather than unconscious perceptual states is not a representational property and that the property of having a blurry conscious character is not a representational property. One might then provide other accounts of some or all of these conscious properties, e.g., functionalist or primitivist accounts. ${ }^{2}$ Having maintained all this, one can still accept that, say, the rightward-motion-y conscious character of the perception is a representational property. If one does then one accepts Weak Representationalism.

As this illustrates, Weak Representationalism is a cautious claim. In view of alleged examples of representational duplication without conscious duplicationexamples that refute Strong Representationalism if the allegations are correct-a weak representationalist can keep "shrinking" the set of conscious properties that can be identified with representational properties. The view thus allows that a very tiny bit of the "what-it's-likeness" of the world can be identified with something representational. ${ }^{3}$ Relatedly, this weak view is accepted by many, and it is uncontested by even greater numbers. For example, Weak Representationalism is not contested by a prominent critic of stronger representationalist claims like Block (2003).

However, David Papineau (2014, 2016) has recently argued that even Weak Representationalism is incorrect. Papineau accepts that many or all mental states are representational. But he thinks that no conscious property can be identified with any representational property. In his words: "I deny that any of the conscious features of

\footnotetext{
1 Thau (2002) might be a strong representationalists. But most who are called (by themselves or others) 'strong representationalists' are not strong representationalists as understood here. Compare notes 3 and 4 below.

2 See Lycan (1998, Sect. 6; ms, Sect. 3) for a functionalist account about the visual character of some conscious states, Tye $(1995,2000)$ for a functionalist account about what makes certain states conscious rather than unconscious, and Chalmers (2004, Sect. 3) for a primitivist account about what makes certain states conscious rather than unconscious.

3 The view of course also allows that a very large bit of this what-it's-likeness is representational. Weak Representationalism thus comes in many degrees of weakness. In practise, philosophers tend to be called 'representationalists' or 'strong representationalists' if they maintain that almost all conscious properties are representational. Tye $(1995,2000)$ is a prominent example of this.
} 
experience are representational" $(2014,3$; see also $2016,324,334) .{ }^{4}$ His reason-or one of his reasons - is that representationalist views fail to account for the fact that conscious character is something "concrete" and "here-and-now". Papineau defends instead a kind of "qualia theory" according to which conscious sensory properties are intrinsic, non-relational properties of subjects. One of the virtues of this theory is, Papineau thinks, that it "bypasses" all the difficulties he has identified for the representationalism $(2014,21)$.

I think Papineau's line of thought is relatively natural. I also think it is relatively widespread. Similar (more-or-less articulated) concerns about representationalist views, and similar ideas to the effect that some qualia theory, adverbial theory, or sense-datum has a significant advantage over representationalist views in this dimension of evaluation can be found in Östman (2013, Ch. 7), Thompson (2008, Sect. 5), and Robinson (2001, Ch. 7, Sect. 2). Sympathies with such thoughts can also be found among some who ultimately accept some or other representationalist view, like Pautz (2010, 282, 293ff.; forthcoming, Ch. 3, Sect. 4) and Kriegel (2011). But I shall here focus only on Papineau.

Although natural, I believe this line of thought is mistaken. I shall try to show that Papineau's view does not bypass the difficulties he identifies for representationalism. In fact, Papineau's view arguably has no advantage at all-even with regard to the present dimension of evaluation-over the representationalist views that he criticises.

The features that concern Papineau about representationalist views do not derive-or do not derive solely-from the representationalism of these views. They (also) derive from the common-factorism of these views. And this commonfactorism is embraced by Papineau himself. In fact it is embraced by most theories of consciousness and perception.

Sections 2 and 3 present Papineau's argument against weak representationalism. ${ }^{5}$ Section 4 presents Papineau's own view. Section 5 assesses Papineau's view. Section 6 spells out the main general lesson.

\section{Representation, propositions, and consciousness}

It is common to suppose that (a) representing something is a matter of standing in a relation to a proposition, and that (b) a proposition is a kind of "abstract" object. Putting (a) and (b) together with Weak Representationalism, we get the view that

\footnotetext{
${ }^{4}$ Papineau tends to restrict this kind of claim to conscious properties of experiences or, sometimes, sensory experiences. I believe he does not intend any substantial restriction here: his view is not that some conscious property of some non-experiential mental state is a representational property. For support of this interpretation, see especially 2016, 342-343. In any case, should some restriction be intended, the present discussion could be modified accordingly.

${ }^{5}$ Or rather, they present one part of his argument. Papineau also argues that representationalism is troublesome because representational properties are plausibly "broad" and conscious properties plausibly are not (2014, Sect. 6; 2016, Sect. 2-4). I will set aside this issue here. I leave open that broadness is a problem for some representationalists, but I note that not all representationalists agree that (all) representational properties are broad (see for example Chalmers 2004; Pautz 2006).
} 
some conscious property of some mental state is identical with some relation obtaining between that state and an abstract object.

Papineau thinks such a view must be incorrect:

propositions are abstract objects, existing outside space and time. ... This seems to me a fatal problem for those representationalists about sensory consciousness who hold that sensory representation consists in subjects being related to propositions. My conscious sensory feelings are concrete, here-andnow, replete with causes and effects. How can their metaphysical nature essentially involve relations to entities that lie outside space and time? (2014, $8)^{6}$

Papineau does not specify what he means by 'concrete' or 'abstract' here. It is therefore unclear whether there is some redundancy in phrases like: "concrete, hereand-now, and replete with causes and effects". To work with a limited number of ideas I will-somewhat arbitrarily_take it that something is "concrete" if and only if it has a spatial or temporal location. On this understanding, individual mental states, processes, and events are uncontroversially concrete as they are uncontroversially located in time. I will also take it that something is "abstract" if and only if it is not concrete. I conjecture that no significantly altered picture will emerge if one works with other explications. ${ }^{7}$

What exactly is problematic with representationalism as presently understood? It is not that, on this view, a mental state's being related to an abstract object lacks spatial or temporal location. Such relations are often established and terminated at particular points in time, e.g., when a subject begins to believe and ceases to believe a certain proposition. The problem is rather, Papineau suggests, that the "remote terms" of such relations - abstract propositions - contribute constitutively to what mental states are like. This, Papineau thinks, cannot be correct. He tries to bring this out by comparing the representationalist view with a "direct realist" view according to which features of one's immediate environment sometimes contribute constitutively to what things are like for a subject. Papineau notes that some find such direct realism "weird," but he urges that things are considerably worse for the representationalist:

It is one thing for a concrete fact in my visible surroundings to contribute constitutively to how I feel. It would be quite another for an abstract proposition outside space and time to do so. This would require my consciousness to somehow reach out and hook onto the denizens of some

\footnotetext{
6 Papineau (2014, 9, note 6) mentions some "more concrete ways of understanding propositions", and he seems later $(2016,345$, note 8$)$ to accept one such a view, but he does not discuss the consequences of such views further. I suspect that, given some views of propositions-in particular, the view that propositions are types of cognitive acts (Soames 2010; Hanks 2015) - the combination of representationalism (weak or strong) and the view that representing something is a matter of standing in a relation to a proposition is much like Papineau's qualia theory. But I will not pursue that thought.

7 For other ways of understanding the abstract-concrete distinction, see Lewis (1986, Sect. 1.7) and Burgess and Rosen (1997, Introduction, Sect. 1).
} 
presumed Platonic realm. I find it hard to make any sense of this $(2014,8$; see also 2016,337$)^{8}$

\section{Propositions aside}

Perhaps representation can be understood as something other than a matter of standing in a relation to a proposition. Propositions and relations to them might be useful to model representational properties even if representing something does not consist in standing in a relation to a proposition, just as, on some accounts, numbers and relations to numbers are useful to model physical quantities, like mass, even if having one of these quantities does not consist in standing in a relation to a number. ${ }^{9}$

Papineau considers this idea. He thinks representationalists encounter problems here too because of a commitment they have regarding sameness of conscious properties. In particular, he thinks representationalists are committed to the view that a veridical perception and a hallucination that "matches" it can be the same in what they are like.

We should actually recognise this common-factor commitment as an optional add-on to representationalism as specified above. One can consistently maintain (a) that some or all conscious properties of mental states can be identified with some representational properties of those states, and allow (b) that veridical perceptions and matching hallucinations are never consciously or representationally fully alike, say, on the ground that some of the conscious and representational properties of the veridical perception are constituted by the particulars they represent. Let us however take it as understood that the common-factor commitment is part of the representationalism that is Papineau's target.

With this understood, consider a Weak Representationalism according to which the "rightward-motion-y" conscious character of a visual perception equals the property of representing rightward motion and according to which this conscious character is duplicated in a matching hallucination. In the hallucinatory case, no relevant individual has the represented rightward motion. So in the hallucinatory case the represented property must be "unattached". And, such an "unattached property" is according to Papineau "abstract" in just the way that propositions are, and understanding conscious character in terms of a relation to such a property is just as problematic as understanding it as a relation to some proposition:

unattached properties are no less abstract than propositions, and so all the earlier difficulties come back. Properties abstracted from any facts into which they enter must be viewed as residing in some Platonic realm outside space and time. Given this, a relation between minds and such abstract entities seems

\footnotetext{
${ }^{8}$ A further worry that Papineau seems to have is that there is something mysterious about any relations between "concrete" and "abstract" things. He notes that representationalists often have complained that "sense-data" are "metaphysically mysterious" and says: "A relationship between concrete minds and abstract propositions strikes me as no less metaphysically mysterious" $(2014,9)$.

9 Compare Field (1978, 1981), Churchland (1979, Sect. 14), Dennett (1983), Davidson (1989), and Matthews (2007).
} 
a poor candidate for the constitution of conscious sensory properties. We have no good model for how an embodied mind might reach out and grasp such abstract Platonic denizens, and even if we did it seems the wrong kind of relation to create the here-and-now features of my conscious life $(2014,15)$.

\section{Papineau's theory}

Papineau proposes that the conscious character of a mental state is an intrinsic and not-essentially-representational feature of the state. By way of analogy, the sentence 'Paris is south of London' has the representational property of being true if and only if Paris is south of London. The sentence (token) also has the intrinsic properties of being black and being formatted in Times New Roman 11 points. These properties, which are in this case instantiated by one and the same thing, can vary independently of one another. Another sentence token can have the same representational property and different intrinsic properties. And an intrinsically identical sentence token could have-if it belonged to a different language-a different representational property.

What relations do we have to these intrinsic properties? Papineau says that when we introspect we are aware of them: "our conscious sensory properties, the ones we are aware of when we introspect, are intrinsic properties of us" $(2014,26 ; 2016)$. But when we do not introspect, we are not aware of them. Instead we just "consciously have" them (2014, 26; see also 2016, 335).

Papineau thinks this view has "all the virtues of representationalism" $(2014,21)$. One of the virtues, as Papineau sees it, is that his theory, like representationalism, is a common-factor theory:

Non-relationism, no less than the representational theory, offers a uniform account of veridical, illusory and hallucinatory experiences. There is no difficulty in explaining why such matching cases should have the same conscious character-this will simply be because they all involve intrinsically identical vehicles of representation (ibid.).

In addition, Papineau thinks his own theory bypasses the difficulties surrounding the representationalist's involvement with "dubious Platonist relations":

non-relationism is under no pressure to build relations to abstract entities into conscious properties. We have seen how representationalists find it hard to avoid the metaphysical awkwardness of invoking relations to non-spatiotemporal abstract entities in their account of conscious properties. Nonrelationism simply bypasses all these difficulties, since it equates conscious properties not with representational properties but with intrinsic vehicle properties. There is no reason to think of these vehicle properties as trading in any dubious Platonist relations (ibid.). 


\section{Assessing Papineau's theory}

Consider again a conscious, blurry, visual experience of rightward motion. Call this (token) experience $\boldsymbol{\varepsilon}$. According to Papineau, $\boldsymbol{\varepsilon}$ 's being like what it is like consists (solely) in $\varepsilon$ 's having certain properties intrinsic to $\boldsymbol{\varepsilon}$. What exactly might these properties be?

That depends on how one understands Papineau's common-factor commitment. I shall in turn consider an exact-sameness interpretation and a weaker, partialsameness interpretation.

On the exact-sameness interpretation, the common-factor commitment is that:

(1) For every experience e, there is a possible experience $\mathrm{e}^{\prime}$ such that e and $\mathrm{e}^{\prime}$ do not overlap but for every conscious property $\mathrm{C}$ : e has $\mathrm{C}$ if and only if $\mathrm{e}^{\prime}$ has $\mathrm{C}$.

There are issues about when exactly individual experiences overlap. Here we need assume nothing more than that experiences of different subjects never overlap. (Experiences of one subject might overlap. For example, my current visual experience might overlap my current overall sensory experience.) (1) thus entails nothing more concerning $\boldsymbol{\varepsilon}$ than that some subject distinct from the subject of $\boldsymbol{\varepsilon}$ could have an experience that has the exact same conscious properties that $\varepsilon$ has.

This common-factor claim is - at least in one dimension-extremely weak. It does not, for example, entail that a hallucination and a veridical experience can have the exact same conscious properties. ((1) is satisfied for all veridical experiences and all hallucinations if: for every veridical experience there is a possible, nonoverlapping veridical experience such that these experiences have the exact same conscious properties, and for every hallucination there is a possible, nonoverlapping hallucination such that these hallucinations have the exact same conscious properties.)

From this relatively weak claim we can infer that what $\boldsymbol{\varepsilon}$ is like does not consist, even in part, in any conscious property instance of $\boldsymbol{\varepsilon}$. Suppose for reductio that:

(2) There is a conscious property $\mathrm{C}$ such that $\boldsymbol{\varepsilon}$ has $\mathrm{C}$ and $\mathrm{C}$ is a property instance of $\varepsilon$.

1 and 2 entail:

(3) There is a possible experience $\mathrm{e}^{\prime}$ and a conscious property $\mathrm{C}$ such that $\varepsilon$ and $\mathrm{e}^{\prime}$ do not overlap and $\mathrm{e}^{\prime}$ has $\mathrm{C}$ and $\mathrm{C}$ is a property instance of $\boldsymbol{\varepsilon}$.

We can safely assume that (3) is false. Property instances go with individuals: it is impossible for an individual $\mathrm{x}$ to have a property instance of a non-overlapping individual $y$. And if (3) is false we have a contradiction, and we can derive the negation of (2) from (1).

If not property instances, what then might the conscious properties of $\varepsilon$ be, compatibly with the present exact-sameness common-factor commitment? I will consider three options. 
A first, Platonist option is that each conscious property of $\varepsilon$-each aspect of what $\varepsilon$ is like-is a universal, understood as an object existing outside space and time. I do not see that this proposal has any advantage over representationalism in the present dimension of evaluation. On this proposal, no aspect of what $\boldsymbol{\varepsilon}$ is like is located in space or time. Therefore, no aspect of what $\varepsilon$ is like is here and now, or in the present sense "concrete".

Might each aspect of what $\varepsilon$ is like be identified instead with an instantiation of a Platonic universal by $\varepsilon$ ? That would not be compatible with the common-factor commitment, as far as I can see. If two individual experiences are non-overlapping, then no instantiation of a universal by one is identical with an instantiation of a universal by the other. Therefore, if what $\varepsilon$ is like is identified with an instantiation of a universal by $\varepsilon$, there can be no experience that is like what $\varepsilon$ is like and that does not overlap with $\boldsymbol{\varepsilon}$.

A second, class nominalist option is that each conscious property of $\varepsilon$ is a class of individuals, namely all individuals that have that property.

As noted above, individual experiences are uncontroversially located in time. For the purposes of the argument, I grant that they are also located in space. Given that, one can-perhaps somewhat reasonably-maintain that conscious properties are on this proposal "concrete" in our present sense. In particular, one can maintain that, being identical with a class of spatiotemporally located individuals, the spatiotemporal location of a conscious property is that of its members. If several things have the property, then this location will be scattered (somewhat in the manner of an archipelago, though bear in mind the temporal dimension). If just one thing has the property, then the location of the property is the location of that individual. ${ }^{10}$

Are conscious properties on the present proposal "here and now"? That is less straightforward. I take it that a conscious property of $\varepsilon$ is "here and now" if and only if it is located when and where $\varepsilon$ is located. Now, if by chance $\varepsilon$ is the only individual that has a certain conscious property, then our present assumptions entail that that property is "here and now". But if some individual experience other than $\varepsilon$ ever has a conscious property that $\boldsymbol{\varepsilon}$ has, then that conscious property will be located only partly where $\varepsilon$ is; it will partly be located elsewhere in time or space.

I do not see that this proposal has any advantage, even with regards to the present dimension of evaluation, over the representationalist views that Papineau criticises. According to the proposal, the conscious character of my current experience partly consists-or may well partly consist-in a distinct individual experience far removed in space and time. To compare this view with representationalism, it is worth recalling that the (putative) "here-and-now problems" for representationalism were limited, and especially so for Weak Representationalism. Weak Representationalism claims only some conscious properties are representational, and the (putative) problems concerned only these. Papineau raises no here-and-now issues about the remaining conscious properties. Moreover, the problem with the

\footnotetext{
${ }^{10}$ Lewis $(1986,83)$ proposes something like this. Armstrong $(1989,98)$ issues a concern about Lewis's proposal.
} 
representational properties were not that they were "abstract", but only that the-or some of the- "remote terms" of the representational relations were.

A third, Aristotelian option is that each conscious property of $\varepsilon$-each aspect of what $\varepsilon$ is like-is a "repeatable" that is or can be "in" many individuals but that cannot exist separately from the individuals it is in, and thus would not exist if nothing had it.

On this view, there is again room for maintaining-perhaps reasonably-that the relevant repeatables are spatiotemporally located in space and time; in particular, where its instantiators are located. If several things have a certain conscious property then that property will again have a scattered location. If just one thing has a conscious property the location of that property will be the location of that individual. Thus, conscious properties will again be "concrete" on our present understanding of the term. And again, a conscious property of $\boldsymbol{\varepsilon}$ will be fully "here and now" if by chance only $\varepsilon$ has it. But as long as one individual experience other than $\varepsilon$ ever has it, the property will be only partly here and now; it will partly be located elsewhere in time or space. The Aristotelian option therefore fares no better than the class nominalist option in accounting for any concreteness and here-andnow-ness of consciousness.

I conjecture that, with regard to accounting for any concreteness and here-andnow-ness of consciousness, there is no way of developing Papineau's theory, understood as having an exact-sameness common-factor commitment, that is more appealing than the Platonist, class nominalist, or Aristotelian construal.

Let me next consider the weaker, partial-sameness interpretation of Papineau's common-factor commitment. On this interpretation, the commitment is that:

(4) For every experience e, there is a possible experience $e^{\prime}$ such that e and $e^{\prime}$ do not overlap but for some conscious property $\mathrm{C}$ : e has $\mathrm{C}$ and $\mathrm{e}^{\prime}$ has $\mathrm{C}$.

Unlike the exact-sameness commitment, the partial-sameness commitment allows that some aspect of what $\varepsilon$ is like consists in a property instance of $\varepsilon$. But it still entails that some aspect of what $\boldsymbol{\varepsilon}$ is like is not a property instance of $\boldsymbol{\varepsilon}$ (since, as before, nothing can be a property instance of $\varepsilon$ and be had by some non-overlapping experience).

By reasoning paralleling that above, we can then conclude that some aspect of what $\varepsilon$ is like is either an abstract universal or something more concrete, but in the latter case something that is—or may well be-partly located remotely from $\varepsilon$ in time or space.

It is again hard to see that this proposal has any advantage over the relevant representationalist views, especially when one considers the ways in which the (putative) "here-and-now problems" for these views were limited. ${ }^{11}$

A natural thought at this point is that what an experience is like might consist solely in (intrinsic) property instances of that experience. However, it is hard, I

\footnotetext{
11 It is also of some (ad hominem) interest to note here that Papineau seems not to consider mere partialsameness common-factorism a live option in his criticism of representationalism (see for example the discussion of look-alikes in 2014, 14).
} 
think, for a common-factor theorist to develop that proposal in a way that makes consciousness come out fully "here and now". Any common-factor theorist must, I suppose, acknowledge some general or "encompassing" element (like a universal or a class) that can somehow recur in, or join together, distinct property instances that belong to distinct experiences; for example, a general rightward-motion-y character that recurs in the rightward-motion-y character of $\boldsymbol{\varepsilon}$ and the rightward-motion-y character of some experience that does not overlap $\varepsilon$. And it seems safe to assume that no such general or encompassing element will be-other than by chance-fully located when and where $\boldsymbol{\varepsilon}$ is located.

In sum, it is, I think, hard to see that Papineau's theory has any advantage, with respect to capturing any concreteness or "here-and-now-ness" of consciousness, over a view that reduces some conscious properties to representational properties. In any case, it seems clear that Papineau's theory does not "simply bypass" the "concreteness" and "here-and-now-ness" issues that he regards as problems for representationalists.

\section{Conclusion}

From the exact-sameness common-factor assumption that two non-overlapping individual mental states can be exactly the same in what they are like, we can infer that what an individual mental state is like cannot be or include a property instance of that state. From that we can in turn infer that what an individual mental state is like cannot be-other than by chance-fully "here and now". At least, that follows on any theory I can think of. If one thinks that (a) the common-factor assumption is plausible and that (b) the conscious character of my current experience is-not just by chance, but necessarily-fully here and now, and not partly at some remote spatial or temporal locations (or in no location at all), this is a dilemma. A closely related dilemma follows from the partial-sameness common-factor assumption that two individual mental states can be partly the same in what they are like. These are dilemmas that seem to be more-or-less equally problematic whether or not one is a representationalist.

Open Access This article is distributed under the terms of the Creative Commons Attribution 4.0 International License (http://creativecommons.org/licenses/by/4.0/), which permits unrestricted use, distribution, and reproduction in any medium, provided you give appropriate credit to the original author(s) and the source, provide a link to the Creative Commons license, and indicate if changes were made.

\section{References}

Armstrong, D. (1989). Universals: An opinionated introduction. Boulder, CO: Westview Press.

Block, N. (2003). Mental paint. In M. Hahn \& B. Ramberg (Eds.), Reflections and replies: Essays on the philosophy of Tyler Burge (pp. 165-200). Cambridge, MA: MIT Press.

Burgess, J., \& Rosen, G. (1997). A subject with no object: Strategies for nominalistic interpretation of mathematics. Oxford: Oxford UP. 
Chalmers, D. (2004). The representational character of experience. In B. Leiter (Ed.), The future for philosophy (pp. 153-81). Oxford: Oxford UP. Reprinted in D. Chalmers, The character of consciousness (pp. 339-371). Oxford: Oxford UP, 2010.

Churchland, P. (1979). Scientific realism and the plasticity of mind. Cambridge: Cambridge UP.

Crane, T. (2000). Introspection, intentionality, and the transparency of experience. Philosophical Topics, $28(2), 49-67$.

Crane, T. (2009). Intentionalism. In A. Beckermann \& B. McLaughlin (Eds.), Oxford handbook to the philosophy of mind (pp. 474-493). Oxford: Oxford UP.

Davidson, D. (1989). What is present to the mind? In J. Brandl \& W. Gombocz (Eds.), The mind of Donald Davidson, (pp. 3-18). Amsterdam: Rodopi. Reprinted in D. Davidson, Subjective, intersubjective, objective: Philosophical essays vol. 3 (pp. 53-67). Oxford: Oxford UP, 2001.

Dennett, D. (1983). Beyond belief. In A. Woodfield (Ed.), Thought and object (pp. 1-95), Oxford: Oxford UP. Reprinted in D. Dennett, The intentional stance (pp. 117-202). Cambridge, MA: MIT Press, 1987.

Field, H. (1978). Mental representation. Erkenntnis 13: 9-61. Reprinted in N. Block (Ed.), Readings in the philosophy of psychology vol. 2 (pp. 78-112). Cambridge, MA: Harvard UP, 1981.

Field, H. (1981). Postscript to mental representation. In N. Block (Ed.), Readings in the philosophy of psychology vol. 2 (pp. 112-114). Cambridge, MA: Harvard UP.

Hanks, P. (2015). Propositional content. Oxford: Oxford UP.

Kriegel, U. (2011). The Veil of abstracta. Philosophical Issues, 21(1), 245-267.

Lewis, D. (1986). On the plurality of worlds. Oxford: Blackwell.

Loar, B. (2003). Phenomenal intentionality as the basis of mental content. In M. Hahn \& B. Ramberg (Eds.), Reflections and replies: Essays on the philosophy of Tyler Burge (pp. 229-258). Cambridge, MA: MIT Press.

Lycan, W. (1998). In defense of the representational theory of qualia (replies to Neander, Rey, and Tye). Philosophical Perspectives, 12, 479-487.

Lycan, W. ms. Block and the representation theory of sensory qualities. Online at http://www.unc.edu/ $\sim$ ujanel/Block\%20and\%20the\%20Representational\%20Theory\%20of\%20Sensory\%20Qualities. pdf. Accessed 1 Feb 2018.

Matthews, R. (2007). The measure of mind: Propositional attitudes and their attribution. Oxford: Oxford UP.

Östman, J. (2013). It's all in the brain: A theory of the qualities of perception. Umeå University: The Department of Historical, Philosophical and Religious Studies.

Papineau, D. (2014). Sensory experience and representational properties. Proceedings of the Aristotelian Society, 114(1pt1), 1-33.

Papineau, D. (2016). Against representationalism. International Journal of Philosophical Studies, 24(3), $324-347$.

Pautz, A. (2006). Sensory awareness is not a wide physical relation: An empirical argument against externalist intentionalism. Noûs, 40(2), 205-240.

Pautz, A. (2010). Why explain visual experience in terms of content? In B. Nanay (Ed.), Perceiving the world (pp. 254-309). Oxford: Oxford UP.

Pautz, A. Forthcoming. Perception. London: Routledge.

Robinson, H. (2001). Perception (2nd ed.). London: Routledge.

Smith, A. D. (2008). Translucent experiences. Philosophical Studies, 140(2), 197-212.

Soames, S. (2010). What is meaning? Princeton, NJ: Princeton UP.

Thau, M. (2002). Consciousness and cognition. Oxford: Oxford UP.

Thompson, B. (2008). Representationalism and the argument from hallucination. Pacific Philosophical Quarterly, 89(3), 384-412.

Tye, M. (1995). Ten problems of consciousness: A representational theory of the phenomenal mind. Cambridge, MA: MIT Press.

Tye, M. (2000). Consciousness, color, and content. Cambridge, MA: MIT Press. 